\title{
Randomized, controlled, superiority study of extended duration of therapy with an intramammary antibiotic for treatment of clinical mastitis
}

\author{
S. McDougall, ${ }^{1 *}$ L. Clausen, ${ }^{1}$ J. Hintukainen, ${ }^{2}$ and J. Hunnam ${ }^{1,3}$ \\ ${ }^{1}$ Cognosco, AnexaFVC, Morrinsville 3300, New Zealand \\ ${ }^{2}$ Faculty of Veterinary Medicine, University of Helsinki, 00014 Helsinki, Finland \\ ${ }^{3}$ Department of Economic Development, Jobs, Transport and Resources, Attwood, Victoria 3049, Australia
}

\section{ABSTRACT}

The objectives of this study were to evaluate the efficacy of therapy of clinical mastitis following intramammary infusion of 2 durations of intramammary antibiotic therapy and to analyze clinical and microbiology data at enrollment or within $4 \mathrm{~d}$ of commencement of treatment as potential predictors of subsequent clinical and bacteriological cure. A total of 304 glands were randomly assigned to intramammary treatment with a combination of amoxicillin, clavulanic acid, and prednisolone either 3 times at 12 -h intervals $(3 \times 12$, n $=156)$ or 5 times at 12 -h intervals $(5 \times 12$ hourly, $\mathrm{n}=$ 148). At enrollment (d 0), assessments were made of the cow's demeanor, rectal temperature, teat-end hyperkeratosis, presence of heat or swelling of the gland, presence of clots in the milk, and California Mastitis Test (CMT) score. Cows were revisited on d 4, 14, and 21 and assessed for rectal temperature, the presence of clots in milk, heat or swelling of the gland, and CMT score. Milk samples were collected from enrolled glands for bacteriology (d 0,4,14, and 21) and for somatic cell count (d 14 and 21). Data were analyzed using generalized linear models. Treatment group was the key independent variable, but herd was included in the models. Other potentially confounding variables were included where associated at the bivariate level. A second series of analyses were undertaken to predict likelihood of clinical and bacteriological cure using the clinical signs cow age and days in milk, as well as bacteriological results at $\mathrm{d} 0$ and 4 . Although we found a higher clinical failure rate in the $3 \times 12$ than $5 \times 12$ hourly treatment group ( $28.2 \pm 5.0$ vs. $13.4 \pm 3.6 \%$, respectively), we noted no difference in bacteriological cure percentage $(73.3 \pm 7.8$ vs. $72.0 \pm 7.4 \%$, respectively). The presence of heat or swelling at $\mathrm{d} 4$, days in milk at initiation of treatment, age of the cow, and change in CMT

Received May 31, 2018.

Accepted January 28, 2019.

*Corresponding author: smcdougall@anexafvc.co.nz score between d 0 and 4 were predictive of clinical and bacteriological cure. We concluded that increasing the duration of treatment resulted in significantly fewer clinical failures, but had no effect on cure proportion, somatic cell count, or new infection rate. Knowledge of cow age and days in milk and clinical signs were predictive of clinical and bacteriological cure proportion and may provide guidance for producers, under veterinary direction, as to when to extend or recommence therapy. Key words: mastitis, therapy, duration, modelling

\section{INTRODUCTION}

Treatment of clinical mastitis incurs significant costs to producers related to the costs of diagnosis, treatment (including the costs of the drug and of milk discarded), on-going production losses, increased probability of deaths and culling of cows, and an increased risk of antimicrobial residues detected in milk. Antimicrobials are commonly used to treat clinical mastitis; the proportion of glands that undergo bacteriological cure following antimicrobial therapy varies between 37 and 84\% (Faull and Ward, 1975; Jarp et al., 1989; McDougall, 1998; Roberson et al., 2004; McDougall et al., 2007a). Cure proportion is affected by bacterial species present, stage of lactation, antimicrobial used, route of administration, presence of antimicrobial resistance, treatment duration, severity of pathology, and immune response (Sol et al., 2000; Taponen et al., 2003; McDougall et al., 2007b; Bradley and Green, 2009).

For time-dependent antimicrobials, such as $\beta$-lactam antimicrobials, increasing duration of therapy is associated with improved bacteriological cure rate (Toutain et al., 2002). For example, bacteriological cure rates were $10.5,35.8,53.7$, and $65.8 \%$ following treatment with $125 \mathrm{mg}$ of ceftiofur on $0,2,5$, or 8 occasions at daily intervals, respectively, for naturally acquired IMI, including Corynebacterium bovis, CNS, Staphylococcus aureus, and Streptococcus species (Oliver et al., 2004). The bacteriological cure rates of naturally acquired Streptococcus uberis infections were 0, 50, 83.3, and 
$100 \%$ following $0,2,5$, or 8 daily intramammary infusions with the lincosamide pirlimycin (Gillespie et al., 2002). Similarly, bacteriological cure rates of Staph. aureus of 6,56 , and $86 \%$ were achieved following 0,2 , or 8 intramammary treatments with pirlimycin (Deluyker et al., 2005). Extending therapy of clinical mastitis associated with $\beta$-lactamase-negative Staph. aureus cases by $2 \mathrm{~d}$, over the baseline therapy of 3 intramammary treatments at 12 hourly intervals, increased the bacteriological cure from 48 to $74 \%$ (Sol et al., 2000). Several intramammary antimicrobials, including amoxicillin/ clavulanic acid, cefuroxime, cloxacillin, penicillin, and pirlimycin, have now been marketed for mastitis therapy with variable on-label durations of treatment.

The benefit of extended duration of therapy varies among both antimicrobials and pathogens, with host factors also contributing to cure rates. Thus, blanket recommendations for extended durations of therapy may not be rational, either from a good stewardship of antimicrobial use perspective or on an economic basis (Swinkels et al., 2005). Producers rarely use microbiology to determine the cause of clinical mastitis or to assess whether bacteriological cure has occurred. Commonly they rely on visual assessment of the milk or the mammary gland to make an assessment as to whether to continue or alter antimicrobial treatment (Ruegg, 2017). Clinical signs associated with mastitis persist for some days after commencement of therapy, and the presence of such signs is not well correlated with bacteriological cure (Pinzón-Sánchez and Ruegg, 2011). Based on clinical signs alone, producers may incorrectly conclude that a gland is not bacteriologically cured and, hence, unnecessarily prolong therapy. If probability of bacteriological cure could be predicted using available cow data (e.g., age, breed, DIM at diagnosis, and so on), progression of clinical signs, or ancillary cow-side tests [such as California Mastitis Test (CMT)], with or without culture preceding initiation of therapy or at $4 \mathrm{~d}$ after initiation of therapy, more rational decisions about whether to prolong therapy could be made.

We hypothesized that extending the duration of antimicrobial therapy of clinical mastitis cases from 3 to 5 intramammary infusions at 12 -hour intervals would reduce the clinical failure proportion, increase bacteriological cure proportion, reduce the risk of new IMI, and increase the prevalence of uninfected glands at the end of treatment. Additionally, we hypothesized that the likelihood of clinical and bacteriological cure could be modeled using the cow's age, DIM, clinical signs, and CMT test results with or without bacteriological data. Finally, we tested the hypothesis that collection of a milk sample for bacteriological $4 \mathrm{~d}$ after initiation of treatment would improving the ability to predict whether bacteriological cure occurred.

\section{MATERIALS AND METHODS}

The study was undertaken with approval of the Animal Ethics Committee of Research Ruakura, New Zealand (Approval number 12644).

Cows $(\mathrm{n}=268)$ were enrolled from 5 spring-calving dairy farms located in the Waikato region of New Zealand. The herds were selected based on willingness to comply with the study protocol. The average herd size was $693(\mathrm{SD}=32$; range $=446-963)$ cows. Herdaverage milk production at the first postpartum milk recording was $23.9(\mathrm{SD}=5.0$, range $=16.4-30.5) \mathrm{kg} /$ cow per day. The herd-average SCC was $135(\mathrm{SD}=85$; range $=62-234) \times 10^{3}$ cells $/ \mathrm{mL}$ at the first production recording of lactation. Cows were enrolled between June 16 and September 27, when the animals were between 0 and 54 DIM. Cows grazed a pasture comprising predominantly of rye grass (Lolium perenne) and white clover (Trifolium repens), but this was supplemented with pasture or maize silage and palm kernel extract to meet the cow's nutrient requirements. Animals were rotationally grazed through the pasture following standard New Zealand management practices. Cows were milked twice daily.

Producers presented cows that they had diagnosed with clinical mastitis (that is, had changes to the milk or the mammary gland). A trained technician undertook examinations within $4 \mathrm{~h}$ of diagnosis, including the demeanor of the cow (normal or depressed), rectal temperature $\left({ }^{\circ} \mathrm{C}\right.$ ), teat-end hyperkeratosis (scored as normal, smooth, rough, or very rough; Mein et al., 2001), an assessment of the gland for presence of heat or swelling [scored on a scale of 1 (none) to 4 (local and systemic signs)], the gross appearance of the milk for the presence of clots [scored on a scale of 1 (none) to 4 (numerous flecks/clots)], and assessed the CMT score (scored on a scale of 0 , trace, 1,2 , and 3 ). Two milk samples $(\sim 5 \mathrm{~mL})$ were collected for bacteriology following aseptic teat end preparation.

Cows were excluded if they had been treated with antimicrobials, nonsteroidal anti-inflammatory drugs, or a corticosteroid in the $30 \mathrm{~d}$ preceding presentation, had a CMT score of 0 , or had a very rough hyperkeratosis score as per European Medicine Agency guidelines (European Medicines Agency, 2017).

Affected quarters of cows were assigned to be treated by intramammary infusion at 12 -h intervals with 200 $\mathrm{mg}$ of amoxicillin (as amoxicillin trihydrate), $50 \mathrm{mg}$ of clavulanic acid (as potassium clavulanate), and 10 mg of prednisolone (Clavulox LC, Zoetis New Zealand Limited, Auckland, New Zealand) on 3 ( $\mathrm{n}=156$ quarters; $\mathbf{3} \times \mathbf{1 2})$ or $5(\mathrm{n}=148$ quarters; $\mathbf{5} \times \mathbf{1 2})$ occasions. Milk was withheld from supply for 120 and $96 \mathrm{~h}$ after the final treatment for the cows treated with $3 \times 12$ and 
$5 \times 12$ treatments, respectively, so both groups had the same total interval from start of treatment to return to supply. Within each herd, cows were randomly assigned within sequentially presented cows to the 2 treatment groups. Treatments were assigned at cow level. The first treatment was administered by a technician, with subsequent treatments undertaken by producers. All treatments were recorded and verified.

Enrolled cows and glands were re-examined by trained technicians at $\mathrm{d} 4( \pm 1)$ for the demeanor of the cow, rectal temperature, hyperkeratosis, presence of heat or swelling, gross appearance of the milk, and CMT. A quarter-level milk sample $(\sim 5 \mathrm{~mL})$ was collected at this time for bacteriology. The CMT score was assessed at d $14( \pm 3)$ and $21( \pm 3)$, and quarter-level milk samples collected for bacteriology $(5 \mathrm{~mL})$ and SCC $(25 \mathrm{~mL})$.

Cows detected with clinical mastitis, or any other disease condition for which antimicrobial therapy was to be used at less than $21 \mathrm{~d}$ after start of treatment, had duplicate milk samples collected aseptically from the affected glands before the antimicrobial therapy was administered. Once the milk samples had been taken, the affected cows were treated as per farm protocol.

\section{Laboratory Procedures}

Milk samples were frozen at $-20^{\circ} \mathrm{C}$ before processing for bacteriology. Bacteriology was undertaken following the procedures of the National Mastitis Council (1999). Briefly, $10 \mu \mathrm{L}$ of milk was streaked onto $0.1 \%$ esculin, sheep blood agar (Fort Richard Laboratories, Auckland, New Zealand), and incubated at $37^{\circ} \mathrm{C}$ for $48 \mathrm{~h}$. The genus or species of bacteria was determined based on colony morphology, Gram stain, esculin reaction, catalase, coagulase, and ChristieAtkins-Munch-Petersen tests. Presumptive coliforms were subcultured on MacConkey agar (Fort Richard Laboratories) and triple iron sugar and motility tests were performed. Somatic cell counting was performed using a fluoro-optic method (Fossomatic 5000, Foss, Hillerød, Denmark) by the Testlink Laboratory (Hamilton, New Zealand).

\section{Power Analysis}

The primary hypothesis to be tested was that the $5 \times 12$ treatment was superior to the $3 \times 12$ treatment in terms of bacteriological cure proportion. It was assumed a priori that the $3 \times 12$ and the $5 \times 12$ groups would have 50 and $70 \%$ cure rates, respectively. Given these assumptions, 80 glands/treatment group (i.e., a total of 160 glands) were required ( $\alpha=0.025 ; \beta=0.2)$. The intention was to enroll at least 230 glands (115/ treatment group) to allow for a $20 \%$ loss to follow-up and a further $20 \%$ to account for clustering of gland within cow. For clinical failure rate, if it were hypothesized that the failure rate was $85 \%$ compared with $70 \%$ for the $5 \times 12$ treatment compared with the $3 \times 12$ treatment, then 93 glands/treatment group (i.e., 186 glands) were required $(\alpha=0.025 ; \beta=0.2)$.

\section{Data Handling and Definitions}

Data, including cow age, breed, calving date, and any previous treatments, were recovered from an electronic database (LIC, Newstead, New Zealand). These data, along with data captured on paper, were included in a purpose-built access database (Microsoft Access 2010, Microsoft Corp., Redmond, WA).

The experimental unit was the individual gland within the cow. Loss to follow-up was defined as having occurred where an animal was excluded where not all data required for analysis was available for that specific cow or quarter. For example, loss to follow-up occurred where a cow died, did not get the appropriate treatment, or was treated with antimicrobials before the post-treatment milk samples being collected.

Clinical failure was defined as having occurred where the producer retreated an enrolled gland within $21 \mathrm{~d}$ of enrollment. Bacteriological cure proportion was defined as the proportion of treated glands from which a pathogen was initially isolated (i.e., pretreatment; d 0) that was not isolated at either d 14 or 21. Where both post-treatment samples were missing or uncollected (e.g., where a cow died or was removed) or were contaminated, cure could not be determined and the case was not included in the bacteriological cure analyses. Where 1 post-treatment sample was not collected or the sample was contaminated and the other sample cultured nothing (i.e., no growth), the cure status of the gland was not defined and the case was not included in the bacteriological cure rate analyses. A gland may have been cured but have had a different bacterium at d 14 or 21; that is, the gland had acquired a new IMI as defined below.

A new IMI was defined as occurring where a previously uninfected gland became infected or where a different pathogen from that isolated pre-treatment was found post-treatment. Where one of the post-treatment samples was no growth and the other sample was missing $(\mathrm{n}=5)$ or contaminated $(\mathrm{n}=13)$, no new IMI status was defined. Where one of the post-treatment samples cultured a pathogen different from that isolated pretreatment and the other sample was missing or contaminated, then the gland was defined as having a new IMI.

As a quarter may fail to undergo bacteriological cure or undergo bacteriological cure but acquire a new IMI, 
the prevalence of no IMI at the end of the treatment course was also assessed. Where one or both posttreatment samples was missing or contaminated, the IMI status post-treatment could not be defined and the case was excluded from this analysis. Note that the $\mathrm{d} 4$ clinical and microbiology data were not used to assess the efficacy of the 2 durations of therapy, but solely as part of the predictive models.

\section{Statistical Analysis}

Assessment of balance of treatment groups for cow age, calving date, DIM, and pre-enrollment clinical data were undertaken using ANOVA (for continuous variables), $\chi^{2}$ (for categorical variables) or a KruskalWallis test for ordinal variables (e.g., calving date).

Outcome variables included clinical and bacteriological cure proportions, the new IMI rate, the proportion of glands that had an IMI based on the post-treatment milk samples, and the natural log of the quarter-level somatic cell count (LnSCC) at d 14 and 21.

Explanatory variables included treatment, herd, age (categorized as 2, 3, 4 to 6, >6 yr), breed (coded as $>12 / 16$ purebred, otherwise crossbred), DIM at enrollment (coded as $\leq 4$ and $>4 \mathrm{~d}$ ), bacterial species at enrollment (coded as no growth, Streptococcus spp., Staph. aureus or others; or as infected vs. not infected), and clinical variables (rectal temperature, hyperkeratosis score, clot score, and heat or swelling score).

Binomial outcomes, including clinical and bacteriological cure proportions, the new IMI rate, and the proportion of glands that were uninfected in both posttreatment milk samples, were analyzed using generalized linear models using a binomial distribution and a logit link function. Initially, bivariate analyses were undertaken, and those variables associated $(P<0.2)$ were backward eliminated from a logistic regression model; variables still present were included in a final generalized linear model where $P<0.05$. Treatment and herd (unless inclusion resulted in the model failing to converge) were included in all models. First-order interactions between treatment and the other variables remaining in the final model were tested. Results are presented as estimated marginal means \pm standard error from the final models.

The LnSCC data were analyzed for the 268 glands for which data were available using a generalized linear mixed model with age (categorized as 2, 3, 4 to 6 , and $>6 \mathrm{yr}$ ), treatment, and days postinitiation of treatment (i.e., d 14 and 21) as main effects. Herd and cow were included as random effects. The first-order interaction of days after treatment and treatment were tested and found to be not significant $(P=0.98)$. Results are pre- sented as estimated marginal means $\pm 95 \%$ confidence intervals from the final models.

The cumulative incidence of clinical failure (i.e., the rate at which enrolled glands were defined as clinical failures by the producers which resulted in additional treatment) was analyzed using Kaplan-Meier survival analysis with the main effect of treatment group tested using a log rank test.

In an attempt to develop predictive models of the risk of clinical mastitis failure and bacteriological cure, a series of models was developed to assess the predictive value of knowledge of the cow data (e.g., age, DIM at diagnosis), the results of clinical examination (e.g., heat/swelling, clot score, and so on), and CMT result with and without bacteriology at d 0 and 4 . Similar models as outlined above were used for these analyses. The predictive value of the variables in the final models were assessed by saving the predicted probability of cure from a logistic regression model, and then undertaking receiver operator curve analysis using these predictions. To aid in understanding the data, the probability of cure was calculated from the coefficients of the logistic regression models, which are presented graphically for predictor variables such as age and DIM at diagnosis.

Statistical significance was declared at $P<0.05$. All analysis was undertaken using IBM SPSS Statistics v20 (http://www-01.ibm.com/software/analytics/ spss/products/statistics/) or STATA s/e v15 (STATA Corp., College Station, TX).

\section{RESULTS}

\section{Cow and Gland Descriptors}

A total of 304 glands from 268 cows were treated. Of the 268 cows, 3 (1\%), 3 (1\%), $21(8 \%)$, and $241(90 \%)$ cows had 4, 3, 2, and 1 glands treated, respectively. A total of 138 cows (156 glands) and 130 cows (148 glands) were treated with the $3 \times 12$ and $5 \times 12$ treatments, respectively.

We found no difference between treatment groups in age, calving date, DIM at enrollment, or rectal temperatures at enrollment, distribution of treatments within each herd, or distribution of cow demeanor score, hyperkeratosis score, udder heat/swelling score, clot score, or CMT score $(P>0.15$; Tables 1 and 2$)$.

\section{Bacteriology}

No bacteria were cultured from 70/302 (23.1\%) enrolled glands, with 42/156 (26.9\%) and 28/146 (19.2\%) quarters from the $3 \times 12$ and $5 \times 12$ groups not isolating any bacterial species, respectively, from samples col- 
Table 1. Mean and SD for age, DIM, and temperature, and median and 25th and 75th percentile for calving date for cows from which glands were diagnosed with clinical mastitis and treated with intramammary antibiotics 3 times at 12 -h intervals $(3 \times 12, \mathrm{n}=156$ glands $)$ or 5 times at 12 -h intervals $(5 \times 12, \mathrm{n}=148$ glands $)$

\begin{tabular}{|c|c|c|c|c|c|}
\hline Variable & \multicolumn{2}{|c|}{$3 \times 12$} & \multicolumn{2}{|c|}{$5 \times 12$} & $P$-value \\
\hline Age (yr) & 4.4 & 2.7 & 4.3 & 2.6 & 0.54 \\
\hline DIM at diagnosis & 6.7 & 11.1 & 5.2 & 8.2 & 0.22 \\
\hline Rectal temperature $\left({ }^{\circ} \mathrm{C}\right)$ & 38.7 & 0.8 & 38.8 & 0.8 & 0.37 \\
\hline
\end{tabular}

${ }^{1}$ Interquartile range $=25$ th and 75 th percentile.

lected before initiation of treatment (d 0). Streptococcus uberis was the most common isolate. We found a difference in distribution of pathogens between treatment groups (Figure $1 ; P=0.03$ ).

Of those glands which were retreated with $21 \mathrm{~d}$ and from which producers collected milk samples $(\mathrm{n}=41$ in total; 26 from the $3 \times 12$ group, and 15 from the $5 \times 12$ group), $46 \%$ were no growth, $29 \%$ were Streptococcus spp., $15 \%$ were Staph. aureus, $7 \%$ were Trueperella pyogenes, and $2 \%$ were contaminated samples. We observed no difference in distribution of bacterial species between the treatment groups $(P=0.74)$.

Table 2. Count of glands for categorical variables for cows (or glands) in which glands were diagnosed with clinical mastitis and treated with intramammary antibiotics 3 times at 12 -h intervals $(3 \times 12)$ or 5 times at 12 -h intervals $(5 \times 12)$

\begin{tabular}{lrrr}
\hline Item & $3 \times 12$ & $5 \times 12$ & $P$-value \\
\hline Herd identifier & & & \\
A & 10 & 9 & 0.99 \\
B & 38 & 33 & \\
C & 11 & 11 & \\
D & 23 & 24 & \\
E & 74 & 71 & \\
Demeanor score & & & \\
Not recorded & 2 & 2 & 0.35 \\
Depressed & 0 & 2 & \\
Normal & 154 & 144 & \\
Milk clot score & & & \\
1 & 31 & 32 & 0.70 \\
2 & 56 & 52 & \\
3 & 31 & 35 & \\
4 & 38 & 29 & \\
Heat/swelling score & & & \\
1 & 27 & 23 & 0.65 \\
2 & 71 & 65 & \\
3 & 37 & 44 & \\
4 & 21 & 16 & \\
California Mastitis Test score & & & \\
Trace & 6 & 6 & 0.69 \\
1 & 17 & 15 & \\
2 & 49 & 38 & \\
3 & 84 & & \\
Hyperkeratosis score & & \\
Normal & & \\
Smooth & 67 & 59 & 0.79 \\
Rough & 74 & 76 & \\
\hline
\end{tabular}

\section{Loss to Follow-Up}

There was a greater overall loss to follow-up for the $3 \times 12$ treatment $(80 / 156,51 \%)$ than the $5 \times 12$ treatment $(45 / 148,30 \% ; P=0.001$; Figure 2$)$.

\section{Clinical Failure}

A total of 152 and 147 quarters were available for final analysis of clinical failure rate in the $3 \times 12$ and $5 \times 12$ treatment groups, respectively (Figure 2 ). The clinical failure proportion was greater in the $3 \times 12$ than in the $5 \times 12$ treatment group $(28.2 \pm 5.0$ vs. $13.4 \pm$ $3.6 \% ; P=0.007$; Figure 3 ), with the proportion varying among ages $(24.5 \pm 4.8,34.8 \pm 9.6,14.9 \pm 5.7$, and $10.9 \pm 3.8 \%$ for $2-, 3-, 4-$ to 6 -, and $>6$-yr-old cows, respectively; $P=0.03$ ). Clinical failure proportion was

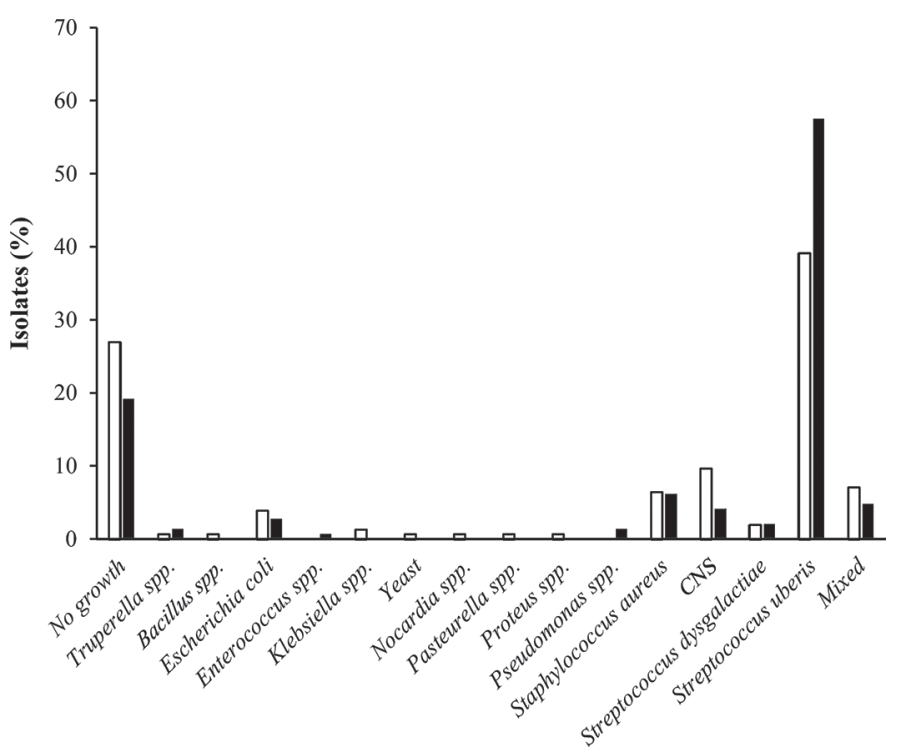

Figure 1. The percentage distribution of bacterial species isolated from individual glands pretreatment in glands diagnosed with clinical mastitis and treated with intramammary antibiotics 3 times at 12-h intervals (white bar; $\mathrm{n}=156$ ) or 5 times at 12 -h intervals (black bar; $\mathrm{n}=146$ ). Note: a quarter was defined as being infected with a mixed growth where 2 distinct bacterial species were present. 


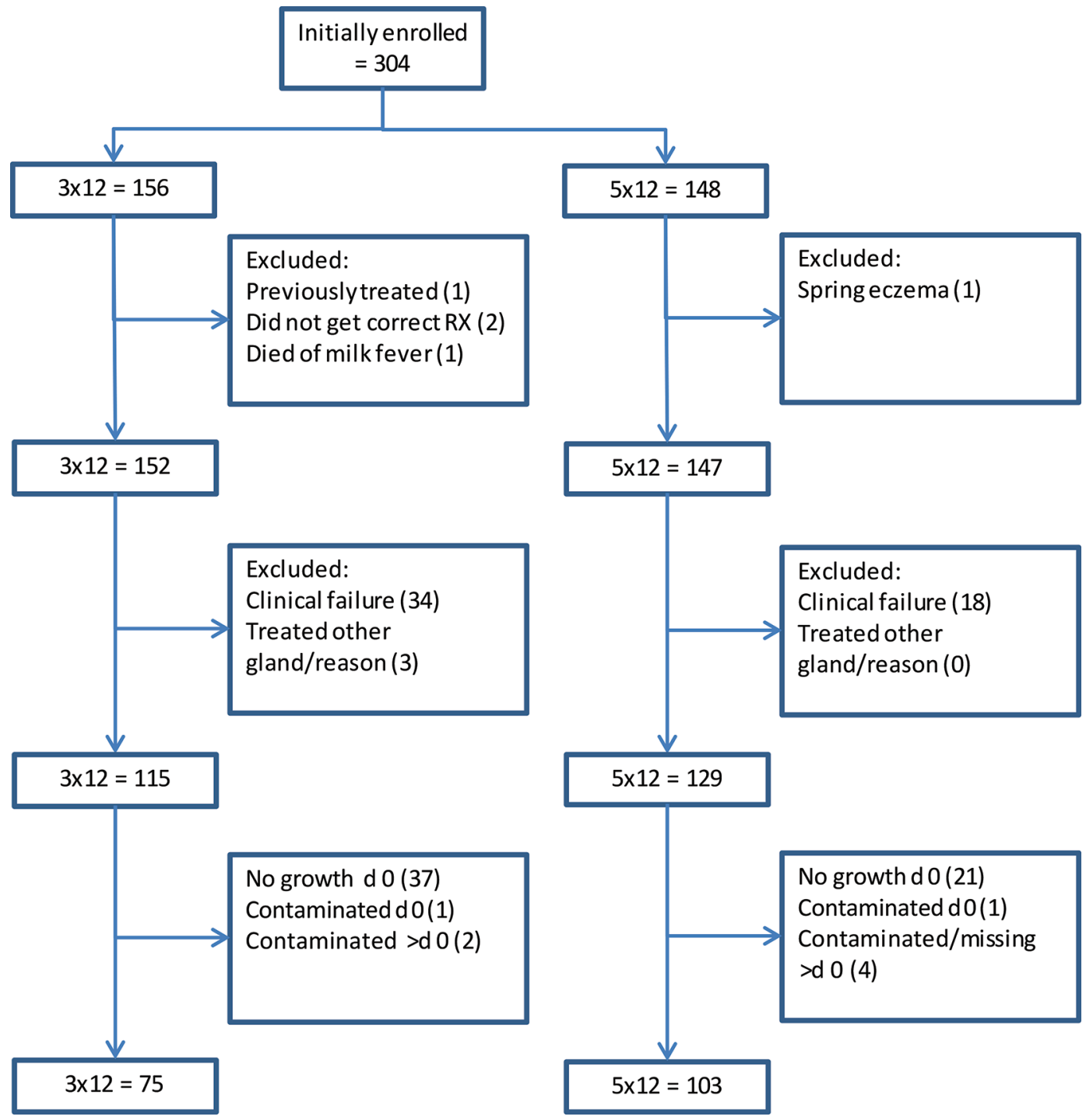

Figure 2. Fate of individual glands diagnosed with clinical mastitis and treated with intramammary antibiotics 3 times at 12 -h intervals $(3 \times 12)$ or 5 times at 12 -h intervals $(5 \times 12)$. $\mathrm{RX}=$ treatment.

greater in glands from which Staph. aureus was isolated at d $0(53.6 \pm 12.5 \%)$ than for Streptococcus spp. (14.1 $\pm 2.9 \%)$, other bacterial species $(11.3 \pm 4.8 \%)$, or no growth $(13.4 \pm 4.1 \% ; P=0.02)$. The proportion of clinical failures among the no growth quarters was 9.5 $\pm 4.5 \%$, whereas it was $21.4 \pm 7.8 \%$ for quarters in the $3 \times 12$ and the $5 \times 12$ treatment groups, respectively. The proportion of clinical failures was $60.0 \pm 15.5$ and $44.4 \pm 16.6 \%$ for quarters infected with Staph. aureus in the $3 \times 12$ and the $5 \times 12$ treatment groups, respectively; $25.3 \pm 5.0$ and $7.4 \pm 2.7 \%$ for quarters infected with Strep. uberis in the $3 \times 12$ and the $5 \times 12$ treatment groups, respectively; and $20.7 \pm 7.5$ and $0.0 \pm 0.0 \%$ for quarters infected with other bacteria in the $3 \times 12$ and the $5 \times 12$ treatment groups, respectively.

\section{Bacteriological Cure Proportion}

A total of 75 and 103 quarters were available for final analysis of bacteriological cure proportion in the $3 \times 12$ and $5 \times 12$ treatment groups, respectively (Figure 2 ). We found no difference in bacteriological cure proportion between the $3 \times 12$ and $5 \times 12$ treatment groups (73.3 \pm 7.8 vs. $72.0 \pm 7.4 \% ; P=0.88)$. Cure proportion tended to be lower in glands from which Staph. aureus had been isolated $(56.0 \pm 19.0 \%)$ than for Streptococcus spp. $(85.6 \pm 3.4 \%)$ or other bacterial species $(71.2 \pm$ $9.4 \% ; P=0.07)$. Cure proportion was lower $(P<0.001)$ in glands diagnosed with clinical mastitis $>4$ DIM compared with $\leq 4$ DIM $(86.0 \pm 4.6$ vs. $53.5 \pm 9.7 \%)$. We found no interaction between treatment group and 
either bacterial species or DIM (both $P>0.2$ ). This model collectively explained $11 \%$ of the variation of the outcome (independent) variable in the final model (i.e., the $\mathrm{R}^{2}$ ). The cure proportion for glands diagnosed at $\leq 4 \mathrm{~d}$ of calving from which Streptococcus spp. were isolated was 0.93, whereas for glands diagnosed at $>4$ d calved from which Staph. aureus was isolated it was 0.35 (Figure 4).

\section{SCC}

Treatment did not affect the $\operatorname{LnSCC}(P=0.95)$, with the LnSCC being $6.82(95 \%$ CI $=6.38-7.26)$ versus $6.61(95 \% \mathrm{CI}=6.23-7.00)$ for the $3 \times 12$ versus $5 \times 12$ treatment at $14 \mathrm{~d}$ post-treatment, respectively, and $6.41(95 \% \mathrm{CI}=6.10-6.72)$ versus $6.30(95 \% \mathrm{CI}=$ $5.98-6.61)$ for the $3 \times 12$ versus $5 \times 12$ treatment at $21 \mathrm{~d}$ post-treatment, respectively. The LnSCC declined with time after treatment $[6.48(95 \%$ CI $=6.02-6.95)$ vs. $6.47(95 \% \mathrm{CI}=6.00-6.94)$ for d 14 vs. 21 , respectively; $P<0.005]$ and tended to vary with age $(P=0.08)$.

\section{New IMI}

A new IMI occurred in $37 / 283(13.1 \%)$ glands. We found no difference in new IMI proportion between the $3 \times 12$ and $5 \times 12$ treatment groups $(14.6 \pm 3.7$ vs. $16.0 \pm$ $4.1 \% ; P=0.51)$, or between herds $(P=0.30)$. Glands with an existing infection (i.e., an IMI was diagnosed at the pretreatment milk sampling) were less likely to acquire a new infection than glands from which no pathogen was grown at this time $(9.8 \pm 2.4$ vs. $23.1 \pm$ $5.9 \% ; P=0.008)$. We observed no interaction between treatment group and either herd or pretreatment IMI (both $P>0.2$ ).

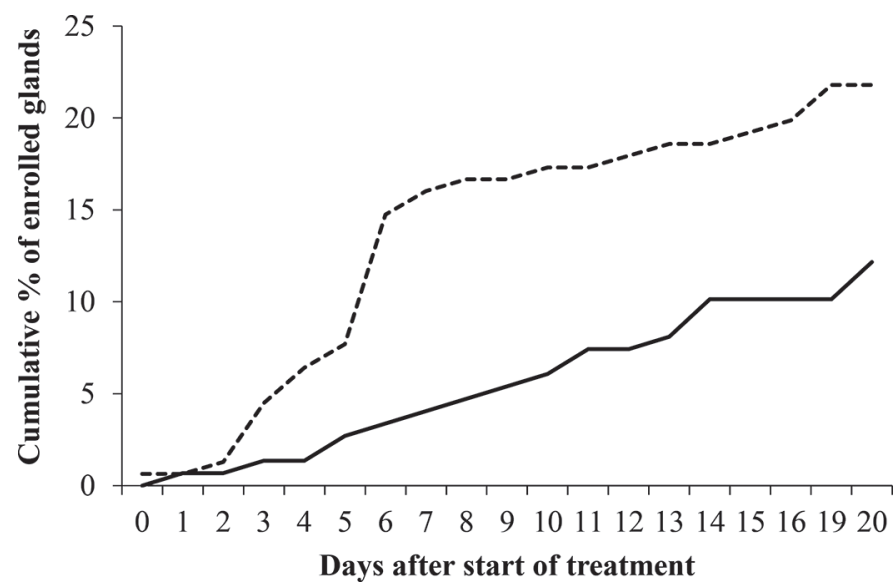

Figure 3. The cumulative percentage of individual glands retreated for clinical mastitis for glands diagnosed with clinical mastitis and treated with intramammary antibiotics 3 times at 12-h intervals $(---; \mathrm{n}=156)$ or 5 times at 12 -h intervals $(-; \mathrm{n}=148)$.

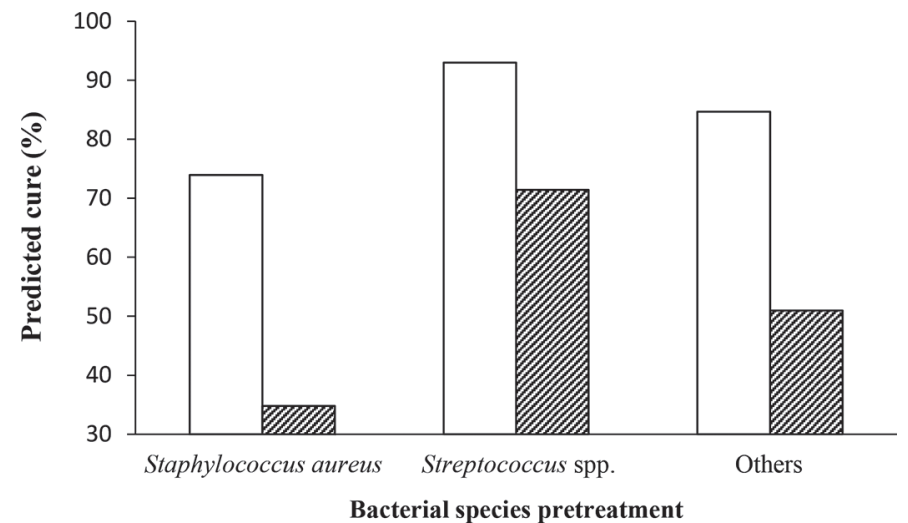

Figure 4. The predicted cure percentage for glands diagnosed with clinical mastitis and treated with intramammary antibiotics at $\leq 4$ (white bars) and $>4 \mathrm{~d}$ (diagonally lined bars) DIM by bacterial species isolated pretreatment.

\section{Prevalence of Infection Post-Treatment}

The post-treatment IMI status could not be determined for $17(5.7 \%)$ glands, as 1 or both of the posttreatment samples were missing or contaminated. For the remaining glands, $211 / 281(75.1 \pm 2.6 \%)$ were uninfected at both post-treatment sampling points (i.e., d 14 and 21). We observed no difference in the proportion of glands with no IMI between the $3 \times 12$ versus $5 \times 12$ treatment groups $(79.8 \pm 4.4$ vs. $78.1 \pm 4.5 \% ; P$ $=0.72)$, and the proportion of uninfected glands did not differ among herds $(P=0.08)$. The proportion of uninfected glands was higher $(P=0.01)$ in 2-yr-old cows compared with 4- to 6-yr-old cows, with other age groups intermediate (Figure 5). We observed no interaction between treatment group and either herd or age group (both $P>0.2$ ).

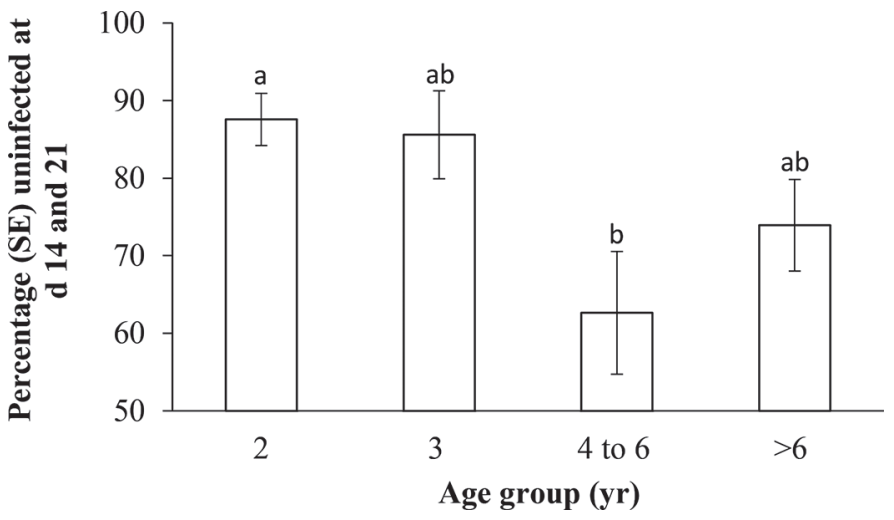

Figure 5. The percentage of glands not infected $( \pm \mathrm{SE})$ at either $\mathrm{d}$ 14 or 21 for glands diagnosed with clinical mastitis and treated with intramammary antibiotics on $\mathrm{d} 0$ by age group. Columns with different letters (a,b) differ at $P<0.05$. 


\section{Prediction of Bacteriological Cure: Inclusion of Data from d 4 Post-Treatment and Clinical Failures}

Bacteria were isolated from 51/304 (16.7 $\pm 2.1 \%)$ samples collected on d 4. Of these glands, 44/51 (86.2 $\pm 4.8 \%$ ) had had 1 or more bacterial species isolated on $\mathrm{d} 0$, and $37 / 44(84.0 \% \pm 5.5 \%)$ of the isolates on $\mathrm{d}$ 4 were the same as those isolated on $\mathrm{d} 0$.

The risk of subsequent clinical failure was greater for glands from which bacteria were isolated on $\mathrm{d} 4$ [22/51 (43.1 $\pm 6.9 \%)]$ compared with glands from which no bacteria were isolated at this time $[30 / 242$ $(12.3 \pm 2.1 \%) ; P<0.001]$. Similarly, the percentage of glands subsequently defined as bacteriologically cured was less for quarters from which bacteria were isolated $[24 / 38(63.2 \pm 7.8 \%)]$ than not isolated $[149 / 172(86.6$ $\pm 2.6 \%)]$ on $\mathrm{d} 4(P<0.001$; Table 3$)$. The bacterial species isolated on d 14 or 21 was the same as that isolated on d 4 in every case where there was a failure of bacteriological cure.

The cure proportion was further modeled with the inclusion of $\mathrm{d}-4$ bacteriology results as well as the gland- and cow-level independent variables. In the final logistic regression model, glands from which bacteria were not isolated at $\mathrm{d} 4$ had a higher cure percentage than those from which bacteria were isolated (84.4 \pm 4.0 vs. $45.3 \pm 12.4 \% ; P=0.001)$. Glands without heat or swelling at d 4 had a higher cure percentage than those with heat or swelling $(79.6 \pm 6.4$ vs. $53.5 \pm 9.3 \%$; $P=0.014)$. Cows $\leq 4$ DIM at initial treatment had a higher cure percentage than cows $>4$ DIM $(81.4 \pm 5.1$ vs. $50.6 \pm 10.9 \% ; P=0.005)$. Cure percentage declined with age $(81.2 \pm 7.5,80.6 \pm 10.5,54.7 \pm 12.6$, and 48.2 $\pm 11.6 \%$ for $2-, 3-, 4$ - to 6 -, and $>6$-yr-old cows, respectively; $P=0.05)$. Inclusion of the d-4 bacteriology results increased the proportion of variance explained (i.e., the $\mathrm{R}^{2}$ ) from 0.11 to 0.23 .

\section{Analysis of d-4 Data and Probability of Bacteriological Cure on a Per Protocol Basis}

At the bivariate level, bacteriological cure proportion was associated with hyperkeratosis at $\mathrm{d} 4$ (categorized as rough vs. not rough), heat and swelling at d 4 (categorized as yes or no), and presence of IMI (i.e., culture positive glands), but not the clot score at $\mathrm{d} 4$ (categorized as present/absent) or rectal temperature. Additionally, the age of the cow and DIM at treatment were offered as potential explanatory variables, as they would be known at the time of assessment.

Inclusion of hyperkeratosis resulted in nonconvergence of the model due to a small number $(\mathrm{n}=12)$ of glands in the rough category. Hence, this variable was removed from further modeling. Presence of IMI at $\mathrm{d}$
Table 3. The quarter-level microbiology results at d 4 compared with the bacteriological cure (assessed at d 14 and 21) for glands diagnosed with clinical mastitis and treated with intramammary antibiotics on d 0

\begin{tabular}{lcc}
\hline & \multicolumn{2}{c}{ Cured $^{1}$} \\
\cline { 2 - 3 } Item & Yes & No \\
\hline Day 4 bacteriology & 149 & 23 \\
No growth & 24 & 14 \\
Culture positive & 0.86 & \\
Sensitivity & 0.38 & \\
Specificity & 0.87 & \\
Positive predictive value & 0.37 & \\
Negative predictive value & & \\
\hline
\end{tabular}

${ }^{1}$ That is, bacteriologically negative at both $\mathrm{d} 14$ and 21 postinitiation of treatment.

4 was removed from the model so that it would simulate the situation where bacteriology results were not available to aid in decision about whether to continue treatment.

In the final generalized linear model, glands without heat or swelling had higher bacteriological cure percentage than those with heat or swelling at $\mathrm{d} 4(86.0$ \pm 4.5 vs. $64.4 \pm 8.2 \% ; P=0.01$ ); glands with a CMT score that declined from d 0 to 4 had a greater cure percentage than those with no change or an increase in CMT score ( $86.3 \pm 3.7$ vs. $63.9 \pm 9.8 \% ; P=0.014)$; cows $\leq 4$ DIM at initiation of treatment had a higher cure percentage than those at $>4$ DIM $(86.3 \pm 3.7$ vs. $64.4 \pm 9.0 \% ; P=0.014)$; and cure percentage tended to decline with age $(88.4 \pm 5.1,83.1 \pm 9.1,67.6 \pm$ 11.3 , and $61.3 \pm 9.2 \%$, for $2-, 3-, 4-$ to 6 -, and $>6$-yrold cows, respectively; $P=0.06$ ). From these data, the probability of bacteriological cure for each age group with and without gland heat or swelling and with and without CMT score reduction was calculated (Figure $6)$.

The probability of cure estimated from the final model resulted in a better prediction of outcome than a random guess (receiver operator curve area under the curve $=0.80 \pm 0.05$; binomial exact $95 \%$ CI $=$ $0.73-0.86 ; P<0.001 ;$ Figure 7$)$.

\section{DISCUSSION}

We assessed the effect of increasing the duration of therapy from $3 \times 12$ to $5 \times 12$ treatments by intramammary infusion with a combination of $200 \mathrm{mg}$ of amoxicillin, $50 \mathrm{mg}$ of clavulanic acid, and $10 \mathrm{mg}$ of prednisolone for naturally occurring bovine clinical mastitis.

Before the study began, the number of cases required was calculated as being 80 glands/treatment group, assuming a difference in bacteriological cure rate of 50 versus $70 \%$ for the $3 \times 12$ versus $5 \times 12$ treatments, re- 


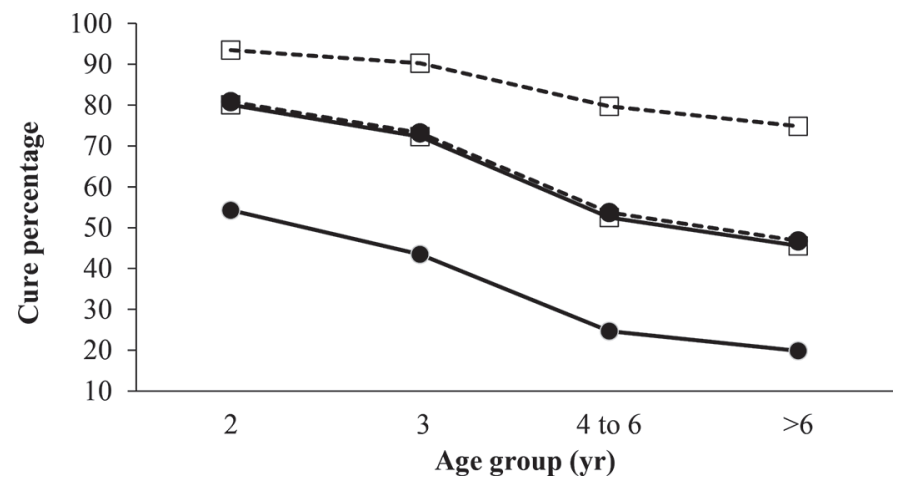

Figure 6. The percentage of glands undergoing bacteriological cure by age group where the mammary gland was still palpably warm $(\bullet)$ or not $(\square)$ on d 4, and which did (- - ) or did not ( - ) have a reduction in California Mastitis Test score between d 0 and 4 , for cows diagnosed with clinical mastitis and treated with intramammary antibiotics on d 0 when they were $\leq 4$ DIM.

spectively. Sufficient cases were enrolled to test this hypothesis, with initially 304 glands assigned and receiving treatment. Following loss to follow up (no growth at d 0 , death, other treatments, clinical failure retreatment), there were 75 and 103 glands in the $3 \times 12$ and $5 \times 12$ groups, respectively, available for analysis of bacteriological cure proportion. The bacteriological cure rate of the $3 \times 12$ treatment group was $73 \%$, compared with $50 \%$ initially assumed for the power analysis. Reassessment of the power of the study found that, assuming a $73 \%$ cure rate of the $3 \times 12$ hourly treatment group with

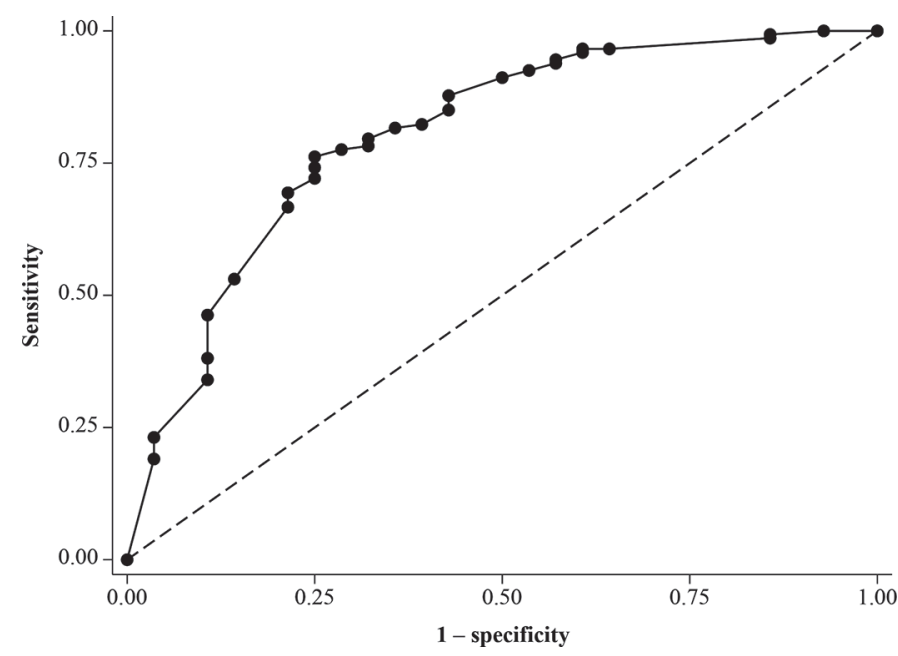

Figure 7. Receiver operator curve derived from the final model predicting cure proportion, which included age group, days calved at enrollment, heat or swelling of the mammary gland at $\mathrm{d} 4$, and change in California Mastitis Test score between d 0 and 4, for cows diagnosed with clinical mastitis and treated with intramammary antibiotics on d 0 . The diagonal reference line represents the line at which the test is not predictive.
72 cases in each group, a bacteriological cure difference of $16 \%$ would have been detected if present.

Extended duration of treatment was associated with a significantly lower (12 vs. $22 \%$ ) proportion of cows retreated within $21 \mathrm{~d}$ of initial treatment than for quarters treated for a shorter duration. The clinical failure rate was broadly similar to previous reports of 14 and $17 \%$ from 2 New Zealand studies (McDougall et al., 2007a,b) and the $13 \%$ reported from the United States (Oliveira and Ruegg, 2014). Recurrence of clinical mastitis tended $(P=0.06)$ to be higher for animals having had a shorter compared with the longer duration of therapy in a US study (Pinzón-Sánchez and Ruegg, 2011). Additionally, recurrence of clinical mastitis varied among herds, increased with increasing cow parity, and increased where bacteriological cure had not occurred (Pinzón-Sánchez and Ruegg, 2011). Clinical signs declined with time post-treatment; for example, only $13 \%$ of cows were clinically cured within $1.5 \mathrm{~d}$ of initiation of treatment compared with approximately $60 \% 5 \mathrm{~d}$ post-treatment and $100 \%$ by $14 \mathrm{~d}$ post-treatment in a Dutch study (Swinkels et al., 2014). To reduce potential bias associated with differences in duration of treatment and an earlier postdiagnosis assessment of the gland and milk, the withdrawal periods in the current study were set such that both treatment groups were returned to the same number of milkings after initiation of treatment. However, as the producers completed the treatments, they were aware of the duration of treatment and were likely to be assessing the status of the milk and mammary gland. Another explanation for persistence or recurrence of clinical signs following treatment is a new IMI. Although an existing infection is protective against another infection (competitive exclusion; Bradley, 2002), different bacteria may be isolated from glands resampled post-treatment, with or without accompanying clinical signs. New IMI occurred in between 0 and $22 \%$ of quarters, depending on the pre-existing pathogen, and numerically there were differences in new IMI rate among 3 treatments assessed in a study (Bradley and Green, 2009). In the current study, we found no effect of treatment duration on the risk of new IMI, but risk of new IMI was higher in quarters from which no bacteria were isolated at enrollment. This may be due to competitive exclusion (Bradley, 2002); alternatively, it may be due to a failure to isolate bacteria at the first sampling, with that infection persisting and being isolated from subsequent samples. This could occur because microbiology is less than $100 \%$ sensitive (Dohoo et al., 2011). The proportion of quarters infected at the end of a treatment protocol (i.e., prevalence of IMI) is a combination of failure of cure of pre-existing infections and new IMI. From an economic point of view, cows remaining 
infected at the end of a treatment protocol were a cost due to likely ongoing production losses and increased likelihood of recurrence of clinical mastitis (Bradley and Green, 2009).

The bacteriological cure proportion did not differ between the treatments. The cure proportion was broadly similar to previous New Zealand studies (McDougall et al., 2007a,b). A priori, we hypothesized that the cure proportions would be approximately 50 and $70 \%$ for the $3 \times 12$ and $5 \times 12$ treatments, respectively; however, the cure rates were $>70 \%$ for both treatments. Thus, numerically the cure proportions were higher than anticipated for the $3 \times 12$ treatment group. As for previous studies, glands infected with Staph. aureus and those treated at greater DIM had lower bacteriological cure rates (McDougall et al., 2007a; Bradley and Green, 2009). Rectal temperature was not predictive of bacteriological cure, unlike a previous study where cows with pyrexia, defined as a rectal temperature $>39.1^{\circ} \mathrm{C}$, had higher overall probability of being pathogen-free post-treatment (Bradley and Green, 2009).

However, the estimate of bacteriological cure proportion may be biased due to the higher clinical failure and, hence, retreatment and exclusion of cows in the $3 \times 12$ treatment group compared with the $5 \times 12$ treatment. This is because the bacteriological cure proportion analysis was, by necessity, undertaken on a per protocol basis; that is, only those glands where all preand post-treatment samples were successfully collected and where no other antimicrobials had been given (which may have interfered with the interpretation of the bacteriology results) could be analyzed.

We found no effect of duration of treatment on the post treatment SCC. Post-treatment SCC was lower in quarters that successfully underwent bacteriological cure (Pinzón-Sánchez and Ruegg, 2011). As bacteriological cure rate did not differ between 2 treatment durations, it is not surprising that the post-treatment SCC did not differ.

A novel finding of our study was that bacteria were isolated from $17 \%$ of glands at $4 \mathrm{~d}$ after initiation of treatment (i.e., 72 and $48 \mathrm{~h}$ after the last treatment for the glands in the $3 \times 12$ and $5 \times 12$ treatment groups, and $24 \mathrm{~h}$ after and $48 \mathrm{~h}$ before the end of the milk withholding periods, respectively). Failure to remove viable bacteria from milk may be associated with the bacterial species, antimicrobial used, route of administration, presence of antimicrobial resistance, treatment duration, severity of pathology, or lack of effective immune response (Sol et al., 2000; Taponen et al., 2003; McDougall et al., 2007b; Bradley and Green, 2009). Neither the concentrations of antimicrobials in milk, nor the MIC for amoxicillin/clavulanic acid for the bacteria isolated on d 4 were analyzed. Thus, we were unable to define whether isolation of bacteria on $\mathrm{d} 4$ was associated with bacteria with an MIC higher than that achieved by treatment. Additionally, no assessment of the cows' immune function was undertaken to determine whether presence of viable bacteria at d 4 was associated with an ineffective immune response. Culture of bacteria at d 4 was associated with subsequent clinical failure and with failure of bacteriological cure. Forty-four percent of those glands from which bacteria were isolated at d 4 had recurrent clinical mastitis, and only $63 \%$ of the glands infected at $\mathrm{d} 4$ were cured. These data suggest that collection of milk samples for microbiology around the end of a treatment program and end of the milk withdrawal period may have some utility, as where bacteria are cultured this was associated with a higher risk of subsequent clinical and bacteriological failure. Although it may appear more logical to collect milk samples before initiation of treatment and make decisions based on bacterial species isolated, the current study found no effect of treatment duration and no duration of treatment by bacterial species at initiation of treatment interaction. In other words, we noted no difference in bacteriological cure rate between the 2 duration of treatments within each bacterial type present at enrollment. The d-4 samples were thus more predictive of clinical and bacteriological outcomes than a sample collected before treatment initiation (d 0). It should be noted that our study was not designed to test the hypothesis that knowledge of microbiology from samples collected before initiation treatment could be used to switch treatments (if appropriate) once microbiology results were known. For example, culture of penicillinresistant Staph. aureus may result in a switch from a narrow spectrum penicillin to a broader-spectrum antimicrobial, as bacteriological cure proportions would be likely improved by this strategy (Sol et al., 2000; Taponen et al., 2003).

Knowledge of the age of the cow, DIM at which treatment commences, the presence of heat or swelling of the mammary gland $4 \mathrm{~d}$ after initiation of treatment, and the change in CMT score between initiation of treatment and $4 \mathrm{~d}$ later were all predictive of whether a gland would bacteriologically cure. These data could be used to advise producers on whether to reinitiate treatment. For example, a 2-yr-old cow, treated $\leq 4$ DIM, that had no heat or swelling present $4 \mathrm{~d}$ later, and in which the CMT score had declined between initiation of treatment and $4 \mathrm{~d}$ later had a $>95 \%$ probability of undergoing bacteriological cure following the initial treatment; thus, using extended therapy would likely have little benefit. Conversely for a cow $>6 \mathrm{yr}$ old, initially treated $>4$ DIM, with heat or swelling on $\mathrm{d} 4$, and which did not have a reduced CMT score between initial treatment and d 4, the bacteriological 
cure rate was predicted to be only $54 \%$; hence, in this case, resuming therapy would appear to be prudent. Taken together these data suggest that there is utility in assessing cows $4 \mathrm{~d}$ after treatment before making a decision to prolong or restart therapy. The practicality of collecting additional data and sample(s), as well as the effectiveness of any interventions based on this additional data needs to be assessed, preferably by a controlled randomized intervention study. Additionally an economic analysis of such an approach needs to be undertaken.

We concluded that increasing the duration of therapy from 3 to 5 treatments at 12 hourly intervals with a combination intramammary therapy of amoxicillin, clavulanic acid, and prednisolone was associated with a reduced risk of clinical failure in the subsequent $21 \mathrm{~d}$. However, no difference in the bacteriological cure proportion or SCC at the gland level was observed between the treatment groups.

Knowledge of the cow's age, DIM, the CMT score change across time, the presence of heat or swelling, and bacteriology results at d 4 were predictive as to whether clinical or bacteriological cure is likely to occur. Use of this data may be beneficial when assessing whether to continue therapy of a cow.

\section{ACKNOWLEDGMENTS}

The technical assistance of Elizabeth Blythe, Ricardo Ferrera, Alan Findlay, Ondine Habgood, Hannah Jensen, Joanne Newell, Michael Truong, and Cathy Yanez (all from Cognosco, AnexaFVC, Morrinsville, New Zealand) is gratefully acknowledged. The cooperation of the producers involved in the study is gratefully appreciated. This study was funded by Pfizer VMRD (Melbourne, VIC, Australia) and Zoetis New Zealand Ltd. (Auckland, New Zealand).

\section{REFERENCES}

Bradley, A. 2002. Bovine mastitis: An evolving disease. Vet. J. 164:116-128.

Bradley, A. J., and M. J. Green. 2009. Factors affecting cure when treating bovine clinical mastitis with cephalosporin-based intramammary preparations. J. Dairy Sci. 92:1941-1953.

Deluyker, H. A., S. N. Van Oye, and J. F. Boucher. 2005. Factors affecting cure and somatic cell count after pirlimycin treatment of subclinical mastitis in lactating cows. J. Dairy Sci. 88:604-614.

Dohoo, I. R., J. Smith, S. Andersen, D. F. Kelton, and S. Godden. 2011. Diagnosing intramammary infections: Evaluation of definitions based on a single milk sample. J. Dairy Sci. 94:250-261.

European Medicines Agency. 2017. Guideline on the Conduct of Efficacy Studies for Intramammary Products for Use in Cattle. European Medicines Agency, London, UK.
Faull, W. B., and W. R. Ward. 1975. Treatment of clinical mastitis Two intramammary formulations compared. Vet. Rec. 96:127-129.

Gillespie, B. E., H. Moorehead, P. Lun, H. Dowlen, D. L. Johnson, K. C. Lamar, M. J. Lewis, S. J. Ivey, J. Halberg, S. Chester, and S. P. Oliver. 2002. Efficacy of extended pirlimycin therapy for treatment of environmental Streptococcus spp and Staphylococcus aureus intramammary infections in lactating dairy cows. Vet. Ther. 3:373-380

Jarp, J., H. P. Bugge, and S. Larsen. 1989. Clinical trial of three therapeutic regimens for bovine mastitis. Vet. Rec. 124:630-634.

McDougall, S. 1998. Efficacy of two antibiotic treatments in curing clinical and subclinical mastitis in lactating dairy cows. N. Z. Vet. J. 46:226-232.

McDougall, S., K. E. Agnew, R. Cursons, X. X. Hou, and C. R. W Compton. 2007a. Parenteral treatment of clinical mastitis with tylosin base or penethamate hydriodide in dairy cattle. J. Dairy Sci. 90:779-789.

McDougall, S., D. G. Arthur, M. A. Bryan, J. J. Vermunt, and A. M. Weir. 2007b. Clinical and bacteriological response to treatment of clinical mastitis with one of three intramammary antibiotics. N. Z. Vet. J. 55:161-170

Mein, G. A., F. Neijenhuis, W. F. Morgan, D. J. Reinemann, J. E. Hillerton, J. R. Baines, I. Ohnstad, M. D. Rasmussen, L. Timms, J. S. Britt, R. Farnsworth, N. Cook, and T. Hemlin. 2001. Evaluation of bovine teat conditions in commercial dairy herds 1 . Noninfectious factors. Pages 347-351 in Proc. Proceedings of the 2nd International Symposium on Mastitis and Milk Quality. American Association of Bovine Practitioners/National Mastitis Council, New Prague, MN.

National Mastitis Council. 1999. Laboratory Handbook on Bovine Mastitis. National Mastitis Council, New Prague, MN.

Oliveira, L., and P. L. Ruegg. 2014. Treatments of clinical mastitis occurring in cows on 51 large dairy herds in Wisconsin. J. Dairy Sci. 97:5426-5436.

Oliver, S. P., B. E. Gillespie, S. J. Headrick, H. Moorehead, P. Lunn, H. H. Dowlen, D. L. Johnson, K. C. Lamar, S. T. Chester, and W. M. Moseley. 2004. Efficacy of extended ceftiofur intramammary therapy for treatment of subclinical mastitis in lactating dairy cows. J. Dairy Sci. 87:2393-2400.

Pinzón-Sánchez, C., and P. L. Ruegg. 2011. Risk factors associated with short-term post-treatment outcomes of clinical mastitis. J. Dairy Sci. 94:3397-3410.

Roberson, J. R., L. D. Warnick, and G. Moore. 2004. Mild to moderate clinical mastitis: Efficacy of intramammary amoxicillin, frequent milk-out, a combined intramammary amoxicillin, and frequent milk-out treatment versus no treatment. J. Dairy Sci. 87:583-592.

Ruegg, P. L. 2017. Practical approaches to mastitis therapy in large dairy herds. Pages 933-948 in Large Dairy Herd Management. 3rd ed. D. K. Beede, ed. American Dairy Science Association, Champaign, IL.

Sol, J., O. C. Sampimon, H. W. Barkema, and Y. H. Schukken. 2000. Factors associated with cure after therapy of clinical mastitis caused by Staphylococcus aureus. J. Dairy Sci. 83:278-284.

Swinkels, J. M., H. Hogeveen, and R. N. Zadoks. 2005. A partial budget model to estimate economic benefits of lactational treatment of subclinical Staphylococcus aureus mastitis. J. Dairy Sci. 88:4273-4287.

Swinkels, J. M., V. Krömker, and T. J. G. M. Lam. 2014. Efficacy of standard vs. extended intramammary cefquinome treatment of clinical mastitis in cows with persistent high somatic cell counts. J. Dairy Res. 81:424-433.

Taponen, S., A. Jantunen, E. Pyörälä, and S. Pyörälä. 2003. Efficacy of targeted 5-day combined parenteral and intramammary treatment of clinical mastitis caused by penicillin-susceptible or penicillin-resistant Staphylococcus aureus. Acta Vet. Scand. 44:53-62.

Toutain, P. L., J. R. E. del Castillo, and A. Bousquet-Melou. 2002. The pharmacokinetic-pharmacodynamic approach to a rational dosage regimen for antibiotics. Res. Vet. Sci. 73:105-114. 